\title{
Health Behavior Change Theories in Physical Activity Pins on Pinterest: A Content Analysis
}

\author{
Samuel Patha*, Cerissa Hayhurst, Nicole Ray, Helen Hilton, Cassidy Hine, Hannah Payne, Josh West \\ Department of Health Science, Brigham Young University, USA
}

\begin{abstract}
Background: Too few adults in developed countries get sufficient daily physical activity, which contributes to the burden of chronic disease. Social media sites may be effective methods of promoting health behavior change, especially when elements of health behavior theory (HBT) are incorporated. However, no research to date has specifically assessed the integration of HBT in physical activity-related pins on Pinterest.

Purpose: A content analysis was conducted to assess the level of HBT in physical activity-related pins on Pinterest.

Methods: A coding rubric was used to code a total of 461 physical activity-related pins for the presence of HBT (Theory of Planned Behavior, Social Cognitive Theory, and Health Belief Model) constructs. A total theory score was computed to provide a global assessment of theory integration. Pin characteristics were also analyzed using descriptive statistics. Adjusted linear regression analysis identified characteristics of pins related to inclusion of HBT in pins.

Results: The average total HBT score was 2.35 out of a possible 9 . Compared to private individuals, pins produced by organizations integrated significantly more HBT constructs (mean 2.23 vs. 2.01; $\mathrm{p}=.005$ ). Other factors such as targeting the whole body, and exercise not requiring equipment also had high integration of HBT. The HBT construct 'outcome expectations' appeared most often in pins.

Discussion: Pinterest pins can be used for health promotion among its users with the integration of HBT in the pins. Select pin characteristics are predictive of theory integration. The average total HBT score of 2.35 in all of the pins studied suggests that physical activity pins are lacking adequate levels of HBT.

Conclusion: Pinterest is an inexpensive, user-friendly platform where health educators can easily generate theory-based pins that may influence physical activityrelated behaviors. Pinterest pins could also be used to disseminate information regarding physical activity to all its users with very low costs.
\end{abstract}

\section{Background}

\section{Physical Inactivity}

Physical inactivity is the $4^{\text {th }}$ leading risk factor for global mortality [1]. It has been estimated that 200,000 - 300,000 deaths occur annually in the United States (U.S.) due to physical inactivity and its attendant consequences [2]. Physically inactive individuals are more likely to be overweight and are at a higher risk for chronic diseases, including coronary heart disease, high blood pressure, and diabetes [3,4]. In the United States, only $21 \%$ of adults get the recommended amount of physical activity as outlined in the 2008 Physical Activity Guidelines [5]. The Centers for Disease Control and Prevention (CDC) estimated about $\$ 75$ billion in obesity attributable healthcare expenditures, which are economic and individual costs as a result of physical inactivity [6].

According to Physical Activity and Health: A Report of the Surgeon General [7], Americans can significantly reduce morbidity and mortality by incorporating moderate physical activity into their daily lives. Increasing physical activity is a major goal for Healthy People 2020 and national health organizations [5,8]. Recommended interventions to increase physical activity range from individual to environmental approaches and include campaigns and health promotion activities.

\section{Social Media and Health Behaviors}

Using the Internet to access health-related information has become a normal behavior. According to a 2011 Pew Research Survey, 74\% of Americans use the Internet and of this population, $80 \%$ have searched online for information on a specific health topic [9]. Search engines and social media are two of the most common methods for retrieving health information from the Internet [10]. Although search engines are more commonly used, social media has been identified as a method that may "maximize the reach and impact of health communication" [11], but only if social media users access quality and reliable information [12]. Many researchers have analyzed the content of internet-based health promotion campaigns, including the inclusion of health behavior theory (HBT). HBT is an important component in health promotion, as it has been associated with increased effectiveness in multiple studies [13-16]. In this study, the Theory of Planned Behavior, Social Cognitive Theory, and Health Belief Model were used without any outcome expectations on which theory would be integrated the most in the pins. Altogether, nine constructs were selected from each of these theories. The theories and constructs were selected based on applicability to Pinterest pins. For example, the construct of 'reinforcements' in Social Cognitive Theory cannot be applied to Pinterest pins because an online

Correspondence to: Samuel Patha, Department of Health Science, Brigham Young University, USA, Tel: 808-492-4499; E-mail: ajaypatha@gmail.com

Key words: health behavior theory; pinterest; content analysis; physical activity pins; health belief model; observational learning; outcome expectations; self efficacy; theory based pins

Received: January 02, 2017; Accepted: January 16, 2017; Published: January 18, 2017 
pin cannot be a constant source of incentives and rewards. However, the construct 'observational learning' was included because Pinterest users can look at the images on the pins and mimic the exercises depicted. It may be that approaches to changing behavior should incorporate multiple theories simultaneously [17]. Theory is often used to assist practitioners in organizing information along certain principles believed to change behavior [17]. Theory could also inform the content of pins on Pinterest in order to be most impactful at changing the user's behavior. With the large number of American adults using web-based resources and social media avenues to access health information, its use in promoting physical activity could be effective in changing behavior, especially if elements of HBT are incorporated.

Pinterest is one social media site that could prove to be useful in health promotion, especially in promoting physical activity. Pinterest is an image-based social networking site that allows users to create virtual boards for topics of interest $[18,19]$. Users can choose to follow boards created by their friends, celebrities, companies, government entities, and others [20]. Though it is only six years old, Pinterest is growing quickly in popularity [21]. Pinterest has more than 70 million active users around the world and is the third most popular social media platform in the United States [22]. Fitness is one of the most searched topics on Pinterest [23]. Because many individuals search on Pinterest for health information, it could be beneficial and effective for examining if Pinterest pins integrate HBT in order to better promote healthy behaviors. The integration of HBT in chronic obstructive pulmonary disease (COPD) pins has recently been evaluated [19], but no research to date has assessed the physical activity-related pins on Pinterest.

\section{Purpose}

The purpose of this study was to determine the extent to which HBT (Theory of Planned Behavior, Social Cognitive Theory, and Health Belief Model) is included in pins related to physical activity on Pinterest, and to identify pin characteristics (such as type of image, body part, user required to click for more info, quantity of images [mosaic, single image], color scheme [vibrant, muted, black and white], pin creator [organization or private user], target sex [male, female, unknown], the amount of text [heavy, light, or no text], the image in focus [photo of a real person with just a body part or whole body], type of physical activity promoted [running, strength training, yoga, etc.], body part targeted [whole body, arms, chin, etc.], outcome expectations of the pin with a specific body image depicted [tan, toned, or thin], outcome expectations of the pin with a specific purpose [weight loss, toned, improving overall health], primary intention of the pin [tone, weight loss, improve health], and intended location of promoted physical activity [home, gym, outside]) that are associated with the inclusion of HBT constructs in those pins. Three research questions were answered to achieve the purpose of the study. They are: Research Question 1 (RQ1): Which HBT constructs are most common in pins? (RQ2): What characteristics of pins are related to HBT, and do professional organizations use more theory in their pins than private users? (RQ3): What characteristics are observed the most and the least in physical activity pins?

\section{Methods}

The design for this study was a content analysis of physical activityrelated pins selected from Pinterest.

\section{Pin Selection and Study Sample}

The sample was collected from Pinterest in October of 2015. A new
Pinterest account with no previous history of pinning was created to ensure search history did not influence results. Querying in Pinterest's search bar using the term, 'exercise fitness' was done to identify an initial sample. The sample pins were found using the search term 'exercise fitness' without a space in between. The first 500 pins generated from this search were pinned for analyses. This methodology for identifying the study sample and the sample size were adapted from other e-health content analyses [19,24-27]. Other content analysis studies of pins had identified relevant pins through boards and then filtered samples by board popularity [19]. However, this was not feasible in this study due to the comparatively high number of physical activity boards available on Pinterest and because Pinterest does not sort individual pins by popularity. Only the first 500 pins were selected because of pins' relevance to the current study, the relevance of the pins' content to the search terms, and also because of time constraints of the study.

\section{Inclusion/Exclusion Criteria}

Only pins that met the criteria for inclusion were included in the study sample. First, only English-language pins were included, which included the text on a pin's image as well as user-generated captions. Pins were only included if they were promoting or depicting physical activity. Pins were considered to be depicting physical activity if the pin contained images of someone exercising, showed exercise machines, or had a list of tips for exercising or fitness. Examples of pins that did not meet the inclusion criteria included pins about fitness clothing or pins depicting food to eat after exercise. After assessing pins for inclusion/exclusion criteria and eliminating duplicates, the final study sample consisted of 461 pins. Out of the 500 pins, 39 pins were excluded because either the text on the pins or the captions were not in English, they did not promote physical activity either with an image of some type of exercise or with no tips for exercise, and if they were advertisements for fitness clothing or diets.

\section{Coding Procedures and Measurement}

Three graduate students trained in HBT coded the pins to evaluate pin characteristics and the extent to which HBT was included. A coding rubric was used to code each pin in the study sample. Codes were entered directly into an electronic database. The coders used a coding instrument that was adapted from a previous content analysis of HBT applications [26-28]. The adaptations for the current study consisted of changes to make the coding relevant to pins.

Table 1 contains a list with definitions of each construct used from Social Cognitive Theory, Theory of Reasoned Action/Planned Behavior, and Health Belief Model that were included in the coding instrument. Nine theoretical constructs were addressed in the instrument. The presence of a construct in a pin resulted in a value of 1 and the absence of the construct was coded as a $0(\mathrm{Yes}=1 / \mathrm{No}=0)$. A total theory score was calculated by summing the values for the nine HBT constructs (range 0 -9). This variable was not normally distributed and a square root transformation was used in order to normalize it. The total theory score was designed to quantify the amount of HBT in Pinterest pins. Furthermore, each pin was coded for the following characteristics: target age group (adolescent, young adult, middle, and unknown), trainer (designed for teaching physical activity to others)- or trainee (designed for following exercise steps)-targeted, citations or attribution for health information included (yes/no), if the pin required a user to click on a hyperlink for opening a new window to access more information about physical activity, the quantity of images (mosaic -multiple images in one pin, single image), color scheme (vibrant - bright colors, muted - not bright or dull colors, black and white), pin creator (organization 
Table 1. Health Behavior Theory Inclusion.

\begin{tabular}{|c|c|c|c|c|}
\hline Construct & Theory & Definition & $\%$ & $\mathbf{N}$ \\
\hline Knowledge & $\begin{array}{l}\text { Social Cognitive } \\
\text { Theory }\end{array}$ & Provides general information or guidelines of how to exercise & 44.03 & 203 \\
\hline Behavioral Capacity & $\begin{array}{l}\text { Social Cognitive } \\
\text { Theory }\end{array}$ & $\begin{array}{l}\text { Provides tools, resources, or environmental changes that make new behaviors easier to } \\
\text { perform (workout is able to be done from home; removal of perceived barriers; exercise does } \\
\text { not require any equipment) }\end{array}$ & 55.1 & 254 \\
\hline Outcome Expectations & $\begin{array}{l}\text { Social Cognitive } \\
\text { Theory }\end{array}$ & Beliefs about the likelihood and value of the consequences of behavioral choices & 70.5 & 325 \\
\hline Observational Learning & $\begin{array}{l}\text { Social Cognitive } \\
\text { Theory }\end{array}$ & $\begin{array}{l}\text { Beliefs based on observing similar individuals or role models perform a new behavior } \\
\text { (celebrity; step by step of a real person) }\end{array}$ & 18.04 & 83 \\
\hline Self-Efficacy & $\begin{array}{l}\text { Social Cognitive } \\
\text { Theory\&Health } \\
\text { Belief Model }\end{array}$ & $\begin{array}{l}\text { Confidence or belief in one's ability to perform a given behavior (encouragement; } \\
\text { empowerment; enabling one to do something; you feel more confident to do something; } \\
\text { testimonial, motivational quotes; smaller steps so one can have mastery experience) }\end{array}$ & 18.66 & 86 \\
\hline Perceived Susceptibility & $\begin{array}{l}\text { Health Belief } \\
\text { Model }\end{array}$ & $\begin{array}{l}\text { Belief about getting a disease or condition (illustrates facts/stats about health problems linked } \\
\text { to not exercising or being physically fit) }\end{array}$ & 2.83 & 13 \\
\hline Perceived Severity & $\begin{array}{l}\text { Health Belief } \\
\text { Model }\end{array}$ & $\begin{array}{l}\text { Belief about the seriousness of the condition or leaving it untreated and its consequences } \\
\text { (Statistics and facts about being overweight or obese; lists negative consequences about } \\
\text { failing to engage in behavior; if untreated it leads to...; inform people about the potential } \\
\text { outcomes of exercising or not exercising) }\end{array}$ & 1.95 & 9 \\
\hline Subjective Norms & $\begin{array}{l}\text { Theory of planned } \\
\text { behavior }\end{array}$ & $\begin{array}{l}\text { An individual's perception of social norms or his/her peers' beliefs about a behavior, that } \\
\text { he or she should or should not perform such behavior (exercise is a socially acceptable } \\
\text { and encouraged activity; people who are important to you think you should engage in this } \\
\text { behavior- family/parent/trainer/celebrity or a physician endorsement) }\end{array}$ & 12.36 & 57 \\
\hline \multirow[t]{2}{*}{ Self Monitoring } & $\begin{array}{l}\text { Social Cognitive } \\
\text { Theory }\end{array}$ & $\begin{array}{l}\text { Provides general information or guidelines about self-monitoring techniques (keeping track } \\
\text { of your exercise is good; calendar to keep track of exercises) }\end{array}$ & 11.28 & 52 \\
\hline & & & Mean & SD \\
\hline Total Theory Score & & & 2.35 & 1.53 \\
\hline
\end{tabular}

Table 2. Statistical Analysis of Parameters of Pins Studied.

\begin{tabular}{|c|c|c|c|c|}
\hline Parameter & Estimate & Standard Error & t-Value & p-value \\
\hline Source - Private User & - & - & - & - \\
\hline Source - Organization & 0.112 & 0.05 & 2.23 & 0.026 \\
\hline Mosaic Image & 0.102 & 0.05 & 2.02 & 0.044 \\
\hline Strength Training & 0.127 & 0.053 & 2.42 & 0.016 \\
\hline Pin targets weight loss & 0.058 & 0.043 & 1.35 & 0.177 \\
\hline User required to click for more info & -0.547 & 0.061 & -9.04 & $<.001$ \\
\hline Pin targets whole body & 0.117 & 0.046 & 2.54 & 0.011 \\
\hline Light to No Text & - & - & - & - \\
\hline Heavy Text & -0.144 & 0.052 & -2.74 & 0.007 \\
\hline Primary purpose to improve overall health & -0.129 & 0.045 & -2.87 & 0.004 \\
\hline Pin uses format " $\mathrm{X}$ to do $\mathrm{Y}$ " (Ex: 10 ways to gain six pack) & -0.135 & 0.039 & -3.47 & $<.001$ \\
\hline Exercise requires equipment & - & - & - & - \\
\hline Exercise does not require equipment & 0.158 & 0.063 & 2.49 & 0.013 \\
\hline Some exercises do not require equipment & 0.178 & 0.089 & 2 & 0.046 \\
\hline No proposed exercise & -0.147 & 0.064 & -2.3 & 0.022 \\
\hline
\end{tabular}

or private user), target sex (male, female, or unknown), the amount of text (heavy - more than $50 \%$ of pin has text, light - less than $50 \%$ of the pin has text, or no text at all), the image in focus (photo of a real person with just a body part or whole body). Pins were also analyzed for the following: type of physical activity promoted (running, strength training, yoga, etc.), body part targeted (whole body, arms, chin, etc.), outcome expectations of the pin with a specific body image depicted (tan - pale brown skin color, toned - noticeable muscle definition and shape, thin), outcome expectations of the pin with a specific purpose (weight loss, tone, improve overall health), primary intention of the pin (tone - from being thin to having increased muscle definition, weight loss - from being fat to thin, improve health) and intended location of promoted physical activity (home, gym, outside)). Outcome expectation coding for 'body type' was done based on if the image on the pin showed a body that was tanned, toned, or thin. Outcome expectations coding for 'purpose of the pin' was done based on if the purpose of the pin was weight loss, getting a toned body, or improving overall health. Outcome expectations for 'body type' and 'purpose of the pin' were coded separately with a possible overlap of outcome expectations on some pins. Codes relating to pin characteristics were derived from Paige et al. and their study of COPD-related pins [19].

\section{Analysis}

To ensure inter-rater reliability among the three coders, each coder coded a common sample of $5.42 \%$ of the final study sample, or 25 pins. A Cohen's Kappa coefficient of 0.60 was calculated, which is considered an acceptable, moderate level of agreement, which includes a range from .41-.60 [29]. Whereas an inter-rater reliability sample of $10 \%$ may be common, $5.42 \%$ was used in this study because an acceptable agreement was achieved. An additional inter-rater reliability sample would have been identified and used had the agreement been unacceptable.

All analyses were conducted using SAS version 9.4. Descriptive statistics were computed to calculate the characteristics of pins in the study sample. An adjusted regression analysis was used to identify 
characteristics of pins associated with the inclusion of HBT in pins, controlling for the other variables in the model. Beta estimates of the parameters (source, mosaic image, strength training, etc.) of pins studied are included in Table 3.

\section{Results}

Table 1 shows the different constructs that were examined in the physical activity pins and how much the total theory score is. Table 2 shows the statistical analysis of the various parameters of the pins studied. Table 3 shows the percentage of pins that have the characteristics studied.

\section{RQ1: Which HBT constructs are most common in pins?}

Table 1 provides the percentage of pins that integrated each of the HBT constructs. After the analysis of the pins using the HBT coding rubric, it was found that the average total HBT score in all the pins was 2.35 out of a possible score of 9 . The most commonly used constructs were 'outcome expectations' (71\%), 'behavioral capacity' (55\%) and 'knowledge' (44\%). Of the 325 pins that contained 'outcome expectations', $89 \%$ depicted image of someone that was thin, $79 \%$ depicted image of someone that was toned, and $64 \%$ depicted image of someone that was tan. Again, in pins containing 'outcome

Table 3. Characteristics of Sample.

\begin{tabular}{|c|c|c|}
\hline Targeted Age & $\%$ & $\mathbf{N}$ \\
\hline Adolescent (12-18 years old) & 4.555 & 21 \\
\hline Young Adult (18-25 years old) & 68.980 & 318 \\
\hline Middle Age (45-65 years old) & 38.612 & 178 \\
\hline Age Unknown & 24.512 & 113 \\
\hline Trainer or Trainee Targeted & $\%$ & $\mathbf{N}$ \\
\hline Trainer & 0.65 & 3 \\
\hline Trainee & 94.78 & 246 \\
\hline Unknown & 4.57 & 21 \\
\hline Citations Included & $\%$ & $\mathbf{N}$ \\
\hline Yes & 1.302 & 6 \\
\hline No & 98.987 & 456 \\
\hline Had to click the Pin to find more info & $\%$ & $\mathbf{N}$ \\
\hline Yes & 70.50 & 325 \\
\hline No & 29.50 & 136 \\
\hline Number of Images & $\%$ & $\mathbf{N}$ \\
\hline Mosaic (multiple images in one pin) & 27.98 & 129 \\
\hline Single Image & 72.02 & 332 \\
\hline Color Scheme & $\%$ & $\mathbf{N}$ \\
\hline Vibrant (bright colors) & 62.47 & 288 \\
\hline Muted (not bright or dull colors) & 31.02 & 143 \\
\hline Black and White & 6.51 & 30 \\
\hline Pin Creator & $\%$ & $\mathbf{N}$ \\
\hline Organization & 80.96 & 370 \\
\hline Private User & 19.04 & 87 \\
\hline Targeted Sex & $\%$ & $\mathbf{N}$ \\
\hline Male & 2.17 & 10 \\
\hline Female & 77.39 & 356 \\
\hline Unknown & 20.43 & 94 \\
\hline Text Amount & $\%$ & $\mathbf{N}$ \\
\hline Heavy text (more than $50 \%$ of the space used for text) & 23.64 & 109 \\
\hline Light text (less than $50 \%$ of the space used for text) & 63.77 & 294 \\
\hline No text & 12.58 & 58 \\
\hline The Image in Focus & $\%$ & $\mathbf{N}$ \\
\hline (can see head)Photo of real person & 57.27 & 264 \\
\hline (other body part)Photo of real person & 32.97 & 152 \\
\hline Neither & 9.76 & 45 \\
\hline
\end{tabular}

expectations', $55 \%$ of them had a purpose of toning, $44 \%$ of them had a purpose of improving overall health, and $35 \%$ had a purpose of weight loss. About $79 \%$ of the pins containing 'outcome expectations' depicted image of someone with toned body and only $55 \%$ of the pins containing 'outcome expectations' had a purpose of achieving a toned body. Out of all the pins studied, the primary intention of physical activity varied with $56 \%$ of pins targeting improving overall health, $46 \%$ targeting toning and $33 \%$ targeting weight loss.

RQ2: What characteristics of pins are related to HBT, and do professional organizations use more theory in their pins than private users?

The variables included in the adjusted regression analysis explained a significant amount of the variance in HBT inclusion (P-Value= $<.001)$. Specifically, characteristics significantly associated with higher levels of HBT included the presence of mosaic images (Beta estimate $=$ 0.102; $\mathrm{P}-$ Value $=0.044)$, depictions of strength training $($ Beta estimate $=$ 0.127; P-Value $=0.016)$, targeting the whole body (Beta estimate $=$ 0.117 ; $\mathrm{P}-$ Value $=0.011$ ), and making reference to physical activity that required little or no equipment (Beta estimate $=0.158$; $\mathrm{P}$-Value $=$ 0.046). Characteristics significantly associated with lower HBT levels included having to click on an external link for more information (Beta estimate $=-0.547$; P-Value $=<0.001)$, heavy amounts of text (Beta estimate $=-0.144 ; \mathrm{P}-$ Value $=0.007)$, targeting overall health (Beta estimate $=-0.129 ; \mathrm{P}-$ Value $=0.004)$, using the format " $\mathrm{X}$ ways to do $\mathrm{Y}$ " (Beta estimate $=-0.135$; $\mathrm{P}-$ Value $=<0.001)$, and no proposed physical activity in the pin (Beta estimate $=-0.147 ; \mathrm{P}-$ Value $=0.022$ ). Compared to private individuals (mean HBT score $=2.01$ ), pins affiliated with organizations (mean HBT score $=2.23$ ) integrated significantly more HBT constructs in pins (Beta estimate $=0.112$; $\mathrm{P}$-Value $=.005$ ).

\section{RQ3: What characteristics are observed the most and the least in physical activity pins?}

Table 3 provides characteristics of the pins in the study sample. Trainees were the most common target audience (95\%), followed by women $(77 \%)$ and young adults $(69 \%)$. Most pins included a single image $(72 \%)$ and contained vibrant colors (62\%). Strength training (39\%) and aerobics (20\%) were the most common type of physical activity promoted yet only included in less than half the pins. Among all the pins, 50\% targeted the whole body, $15 \%$ targeted abdominals, $10 \%$ targeted legs, $8 \%$ targeted buttocks, and $7 \%$ targeted arms. About $44 \%$ of the pins were promoting physical activities at home, $28 \%$ at gym, and $13 \%$ outdoors. Organizations created most of the pins $(81 \%)$ with very few providing citations (1.3\%). Most of the pins $(64 \%)$ had very light text and about $57 \%$ showed a photo of a real person.

\section{Discussion}

The majority of pins in the sample targeted trainees, women, and young adults. This is not surprising, given that $42 \%$ of online women and 34\% of people ages 18-29 of internet users are Pinterest users [30]. With the majority of pins being directed at women and young adults, there leaves a gap for other uses. The number of men and individuals ages 50 and older using Pinterest significantly increased from 2013 to 2014 [30]. In 2014, 13\% of all male internet users and $44 \%$ of all age 50 and older adult internet users also used Pinterest, compared to $8 \%$ and $23 \%$ respectively from 2013 [30]. These statistics are evidence to the fact that the demographic makeup of Pinterest users has shifted.This shift requires health professionals and organizations developing pins for use in health promotion to adjust the content and focus of the pins they create to match the demographic makeup of Pinterest users. 
The majority of pins addressed strength training, with aerobic training being the next most common type of exercise targeted on Pinterest. It has been recognized that in comparison to aerobic training, strength training as a preventive health practice has received far less emphasis in public health, despite findings indicating that strength training is just as effective in preventing the onset of chronic diseases [31]. Indeed, while many health promotion efforts target increasing physical activity [32] and strength training as a component of national physical activity recommendations [33], few health promotion activities focus on the importance of strength training specifically. Pinterest may be particularly useful in providing tutorials, information, and ideas about strength training for women, who are less likely to engage in strength training exercises [34,35].

It was also discovered that the majority (98\%) of physical activity pins did not contain citations, which has been identified as a challenge in the use of social media in health promotion along with other drawbacks such as presenting opinion as fact as well as blind authorship [36]. This lack of credibility of exercises posted on pins may pose an unique safety concern for women who may be engaging in strength training for the first time after being inspired by Pinterest pins. However, on the other hand, the use of social media sites like Pinterest provides many unique benefits in health promotion, including a low cost, interaction among users, and rapid transmission among individuals [36].

'Outcome expectations' were integrated into pins more often than any other HBT construct. Nearly 9 out of 10 pins with 'outcome expectations' portrayed a thin physique, and between 6-7 out of 10 pins showed either a tan or toned body. These results may be concerning in light of recent research on the effects of social media on body image. Previous studies have demonstrated associations between young women's body image concerns and their time spent on Facebook [37]. Ghaznavi and Taylor (2015) studied Twitter- and Pinterest-based images labeled with the hashtag "thinspiration" [38]. They concluded that frequent exposure to images of thin women makes women more likely to accept these images as a desirable reality. While concern for personal appearance has been identified as a major motivator for many individuals to engage in physical activity [39], utilizing these tactics in physical activity promotion may backfire. Body image concerns have been demonstrated to affect many health behaviors, including higher levels of dieting, unhealthy weight control behaviors, lower fruit and vegetable intake, and interestingly, lower levels of physical activity [40].

'Behavioral capacity' and 'knowledge' constructs were integrated into about half of the pins. As Bandura suggests, when there are no impediments (to physical activity), it is easier to perform said behavior $[41,42]$. A pin integrated with 'behavioral capacity' and 'knowledge' may help overcome perceived barriers and functionally make behavior easier to do. 'Perceived susceptibility' and 'perceived severity' were integrated the least. Organizations may benefit from integrating 'perceived susceptibility' and 'perceived severity' in a creative way in their pins as they have been shown to increase adherence to an exercise plan $[43,44]$. 'Observational learning' could also be termed modeling and it could help motivate Pinterest users to be more physically active by observing the actions of others [14]. Integration of 'observational learning' may also provide Pinterest users with "coping models" who have overcome similar struggles or barriers [45]. 'Self-efficacy' is another factor associated with increases in physical activity [46]. Future efforts to include 'self-efficacy' could include a sequence of instructional photos depicting physical activity techniques accompanied with encouraging statements.
High amount of text on pins was associated with low HBT score. Whereas, targeting whole body on the pin is associated with higher HBT score. High levels of integration of constructs such as 'behavioral capacity', 'knowledge', and 'outcome expectations' showed that Pinterest pins could be used to disseminate knowledge about physical fitness and step-by-step instructions on exercises among Pinterest users. Leveraging 'observational learning' in these pins could be a great way to improve self-efficacy among users who cannot read or in users who are contemplating exercise for the first time or after a long break.

\section{Conclusion}

The findings presented herein may be significant to health educators that wish to use Pinterest pins either for personal use to gather information, or to recommend them for use by another individual. Pinterest is a user-friendly platform where health educators with limited technology skills could begin with little training to generate theory-based pins.

Pinterest has become a popular resource for health information and to the extent that pins integrate HBT may be more likely to influence physical activity-related behaviors. The lack of HBT could be viewed as both a caution for health educators and an opportunity for collaboration to improve pins with an effort to influence physical activity-related behaviors. The lack of citations on pins from organizations could be viewed as a caution for women who may be engaging in strength training for the first time, this gap can be filled by organizations by conducting increased research on evidence based studies before publishing their pins.

The most observed HBT construct in the pins were 'outcome expectations' and 'behavioral capacity' and the least observed HBT constructs in the pins are 'perceived susceptibility' and 'perceived severity'. This could be another area for health educators to focus on to make sure that the constructs with low prevalence are integrated into Pinterest pins in the future. Training health educators to leverage userfriendly social media platforms, such as Pinterest, to promote physical activity using HBT is recommended.

Only $0.65 \%$ of the pins studied were targeted towards trainers and about $95 \%$ of the pins were targeted towards trainees. Fitness instructors could use this information to refer clients to Pinterest for information and support related to physical activity.

Although the combination of constructs of the HBT studied is not evidence based for positive influence on physical activity or health, it is assumed that it is better to have some HBT than none at all. Therefore, the extent to which these pins actually influence physical activity should be the focus of future research. This could be done through a prospective cohort study or a randomized control trial.

\section{Limitations}

This exploratory study used a content analysis approach, which may be subject to individual interpretation. Inter-rater reliability was calculated to mitigate the effects of subjectivity and maintain a level of consistency among coders. Researchers were unable to gather a randomized sample of physical activity pins because of the lack of function on Pinterest to number each pin in the search results to pick and choose certain random numbers. Through professional consultation of asking frequent Pinterest users, key search terms were determined to most closely resemble the average user's behavior on Pinterest. Even though total HBT score was measured, the extent to which theory integration occurs in each pin was not measured in this study. 


\section{Acknowledgments}

This research project is a team effort of Samuel Patha, Cerissa Hayhurst, Nicole Ray, Helen Hilton, Cassidy Hine, Hannah Payne, and Josh West. We are grateful for the support of Department of Health Science, Brigham Young University.

\section{References}

1. World Health Organization. Global recommendations on physical activity for health.

2. Brownson RC, Boehmer TK, Luke DA (2005) Declining rates of physical activity in the United States: what are the contributors? Annu Rev Public Health 26: 421-443. [crossref]

3. National Heart, Lung, and Blood Institute. What causes overweight and obesity? http:// www.nhlbi.nih.gov/health/health-topics/topics/obe/causes. Published July 13, 2012. Accessed October 7, 2015.

4. World Health Organization. Physical inactivity: a global public health problem. http:/ www.who.int/dietphysicalactivity/factsheet_inactivity/en/\#. Updated 2015. Accessed November 19, 2015.

5. Pate RR, Yancey AK, Kraus WE. (2010) The 2008 physical activity guidelines for Americans: implications for clinical and public health practice. Am J Lifestyle Med 4:209-217.

6. California Department of Public Health. The economic costs of physical inactivity, obesity, and overweight in California adults: healthcare, workers' compensation, and lost productivity. https://www.cdph.ca.gov/HealthInfo/healthyliving/nutrition/ Documents/CostofObesityToplineReport.pdf. Published April 2005. Accessed November 16, 2015.

7. Centers for Disease Control and Prevention. Physical activity and health: a report of the Surgeon General. http://www.cdc.gov/nccdphp/sgr/. Published November 17, 1999. Accessed October 6, 2015.

8. Centers for Disease Control and Prevention. Health People - Physical activity. https:// www.healthypeople.gov/2020/topics-objectives/topic/physical-activity. Updated 2016. Accessed November 4, 2015.

9. Fox S. (2011) The social life of health information, Published May 12, 2011. Accessed November 3, 2015.

10. De Choudhury M, Morris MR, White RW. (2014) Seeking and sharing health information online: comparing search engines and social media. ACM Dig Lib 13651376.

11. Chou WS, Hunt YM, Beckjord EB, Moser RP, Hesse BW. (2009) Social media use in the United States: implications for health communication. J Med Internet Res 11(4): e48. [crossref]

12. Moorhead SA, Hazlett DE, Harrison L, Carroll JK, Irwin A, et al. (2013) A new dimension of health care: systematic review of the uses, benefits, and limitations of social media for health communication. J Med Internet Res 15(4): e85. [crossref]

13. Fishbein M, Yzer MC. (2003) Using theory to design effective health behavior interventions. CommuTheor 13:164-183.

14. Glanz K, Bishop DB (2010) The role of behavioral science theory in development and implementation of public health interventions. Annu Rev Public Health 31: 399-418. [crossref]

15. Juul L, Andersen VJ, Arnoldsen J, Maindal HT. (2016) Effectiveness of a brief theorybased health promotion intervention among adults at high risk of type 2 diabetes: oneyear results from a randomised trial in a community setting. Prim Care Diabetes 10(2): 111-120. [crossref]

16. Lopez LM, Tolley EE, Grimes DA, Chen-Mok M (2009) Theory-based strategies for improving contraceptive use: a systematic review. Contraception 79: 411-417. [crossref]

17. Achterberg C, Miller C. (2004) Is One Theory Better than Another in Nutrition Education? A Viewpoint: More Is Better. Journal of Nutrition Education and Behavior $36(1): 40-42$.

18. Social Media Today. How to champion the visual discovery tool pinterest. http:// www.socialmediatoday.com/content/how-champion-visual-discovery-tool-pinterest. Published September 2, 2014. Accessed October 11, 2015.

19. Paige SR, Stellefson M, Chaney BH, Alber JM. (2015) Pinterest as a resource for health information on chronic obstructive pulmonary disease (copd): a social media content analysis. Am J Health Educ 46: 241-251.
20. O'Reilly L. (2014) Pinterest is tooling up to act a lot more like facebook. Published September 30, 2014. Accessed October 27, 2015.

21. D'Onfro J. (2015) How pinterest plans to spend its new millions and why it only hires nice employees, according to its cofounder. Published May 11, 2015. Accessed October 5,2015 .

22. Wilkinson Z. (2013) Oh, how pinteresting! an introduction to pinterest. Libr Hi Tech News 30(1): 1-4.

23. Smith C. (2014)This is the behavior on pinterest that makes the social network so attractive to marketers. Published April 17, 2014. Accessed November 19, 2015.

24. Briones R, Nan X, Madden K, Waks L (2012) When vaccines go viral: an analysis of HPV vaccine coverage on YouTube. Health Commun 27: 478-485.[crossref]

25. Bromberg JE, Augustson EM, Backinger CL (2012) Portrayal of smokeless tobacco in YouTube videos. Nicotine Tob Res 14: 455-462.[crossref]

26. Lister C, West JH, Cannon B, Sax T, Brodegard D (2014) Just a fad? Gamification in health and fitness apps. JMIR Serious Games 2: e9.[crossref]

27. Payne HE, Moxley VB, MacDonald E (2015) Health Behavior Theory in Physical Activity Game Apps: A Content Analysis. JMIR Serious Games 3: e4.[crossref]

28. West JH, Hall PC, Arredondo V, Berrett B, Guerra B, Farrell J. Health behavior theories in diet apps. J Consum Health Internet. 2013; 17(1):10-24

29. Landis JR, Koch GG (1977) The measurement of observer agreement for categorical data. Biometrics 33: 159-174.[crossref]

30. Duggan M, Ellison NB, Lampe C, Lenhart A, and Madden M. Demographics of key social networking platforms. http://www.pewinternet.org/2015/01/09/demographicsof-key-social-networking-platforms-2/. Published January 9, 2015. Accessed October 2, 2015.

31. Phillips SM, Winett RA. (2010) Uncomplicated resistance training and health-related outcomes: evidence for a public health mandate. Curr Sports Med Rep 9(4): 208-213. [crossref]

32. Center for Disease Control and Prevention. Promoting healthy eating and physica activity for a healthier nation. http://www.cdc.gov/healthyyouth/publications/pdf/ppch7.pdf. Published 2010. Accessed December 11, 2015.

33. Presidents Challenge. Progression and resistance training. https://www. presidentschallenge.org/informed/digest/docs/200509digest.pdf. Published September 2005. Accessed October 24, 2015.

34. Ebben WP, Jensen RL (1998) Strength training for women: debunking myths that block opportunity. Phys Sportsmed 26: 86-97.[crossref]

35. Center for Disease Control and Prevention. Trends in strength training --- United States, 1998--2004. 55(28);769-772

36. Vance K, Howe W, Dellavalle RP (2009) Social internet sites as a source of public health information. Dermatol Clin 27: 133-136, vi.[crossref]

37. Fardouly J, Diedrichs PC, Vartanian LR, Halliwell E (2015) Social comparisons on social media: the impact of Facebook on young women's body image concerns and mood. Body Image 13: 38-45.[crossref]

38. Ghaznavi J, Taylor LD2 (2015) Bones, body parts, and sex appeal: An analysis of \#thinspiration images on popular social media. Body Image 14: 54-61.[crossref]

39. Kilpatrick M, Hebert E, Bartholomew J. (2005) College students' motivation for physical activity: differentiating men's and women's motives for sport participation and exercise. J Am Coll Health 54(2):87-94. [crossref]

40. Neumark-Sztainer D, Paxton SJ, Hannan PJ, Haines J, Story M (2006) Does body satisfaction matter? five-year longitudinal associations between body satisfaction and health behaviors in adolescent females and males. $J$ Adolescent Health 39(2):244-251. [crossref]

41. Bandura A (2004) Health promotion by social cognitive means. Health EducBehav31 143-164.[crossref]

42. Gaines A, Turner L. (2009) Improving fruit and vegetable intake among children: a review of interventions utilizing the social cognitive theory. Calif J Health Promot 7(1):52-66.

43. Janz NK, Becker MH (1984) The Health Belief Model: a decade later. Health Educ $Q$ 11: 1-47. [crossref]

44. Mirotznik J, Feldman L, Stein R. (1995) The health belief model and adherence with a community center-based, supervised coronary heart disease exercise program. $J$ Commun Health2:233-247. [crossref] 
Patha S (2017) Health Behavior Change Theories in Physical Activity Pins on Pinterest: A Content Analysis

45. McAlister A, Perry C, Parcel G. (2008) How individuals, environments and health behaviors interact: social cognitive theory. In: Glanz K, Rimer BK, Viswanath K, eds. Health Behavior and Health Education: Theory, Research and Practice. 4th ed San Francisco, CA: Jossey-Bass 169-185.
46. Dzewaltowski D, Noble JM, Shaw JM. (1990) Physical activity participation: social cognitive theory versus the theories of reasoned action and plannedbehavior. $J$ Sport Exercise Psy 12(4): 388-405.

Copyright: (C2017 Patha S. This is an open-access article distributed under the terms of the Creative Commons Attribution License, which permits unrestricted use, distribution, and reproduction in any medium, provided the original author and source are credited. 